\title{
Correction to: Resolving pathogenicity classification for the CDH1 c.[715G>A] (p.Gly239Arg) variant
}

Zarina Yelskaya - Angela G. Arnold · Vanessa J. Marcell (1) - Laura H. Tang · Erin E. Salo-Mullen • Vivian E. Strong • Zsofia K. Stadler $\cdot$ Liying Zhang (1)

Published online: 27 April 2021

(c) The Author(s), under exclusive licence to European Society of Human Genetics 2021

Correction to: European Journal of Human Genetics https://doi.org/10.1038/s41431-021-00825-w
In the original publication of the article, the sixth author's name was incorrect. The correct name is Vivian E. Strong, not Vivian Strong. 